\title{
BUILDING THE E-LEARNING ENVIRONMENT
}

\section{Creating The Technical Side of Peace}

Tina Ebey, M.A., M.F.A. PhD candidate ${ }^{1}$, Olivier Urbain, $\mathrm{PhD}^{2}$

${ }^{1}$ Pacific Research Center, Inc.; ${ }^{2}$ Transcend Peace University and Soka University, Japan.

Abstract: In addition to academic technical training, distance learning concepts must embody forefront global human issues influencing human security. The purpose in writing this paper is to continue to become more motivated by the potential for cultivating a culture of peace with the awareness of how much wisdom based technical knowledge is necessary to ensure humanity's safety. Coursework from Soka University in Japan and an online network of artists from the TAP network have been selected as case studies to illustrate applied uses of technical learning in the arts and sciences building a global dimension to peaceful dialog and student driven learning.

Key words: human security; applied technical knowledge; ethical education; web-based conferencing.

\section{HUMAN SECURITY ISSUES DETERMINE FOREFRONT TRAINING}

The purpose of this paper is to identify an educational perspective based on academic training using electronic media and distance education toward building a culture of peace. The goals include learning to teach in a student driven environment and inviting the learner to develop skill to teach the teacher by applying understanding to issues of human security in the global community.

We have singled out the 2004 Peace Proposal of Daisaku Ikeda as a resource to create perspective. Issues bring focus to learning by siting attainable goals as parameters for scientists during their years of professional training and skill building with problem solving. The internet was originally 
designed as an instrument of DARPA, the American Department of Defense. As an agency of the U.S. defense industry why not turn it from a sword into a plowshare? With this goal in mind creating motivation in e-learning to globally relevant peace education becomes a technical challenge.

Daisaku Ikeda, President of the Soka Gakkai International and author of twenty peace proposals over the last two decades to the United Nations writes that in the world today 860 million adults are said to be illiterate, and 121 million children have no access to school. The Education for All campaign, spearheaded by UNESCO, aims to realize universal basic education with concrete benchmarks for achievement. Last year was also the start of the United Nations Literacy Decade (2003-2012). Two thirds of the illiterate are women. Creating learning methodology that embraces the lives of these women represents a huge challenge affecting families and the community. This challenge is both technical and practical demanding that teaching methods in the e-learning environment apply to their lives and cultivate skills in a relevant and humanistic way.

\section{ETHICAL TECHNICAL EDUCATION}

Our purpose in bringing these issues forward is to serve as a catalyst for moral criteria. It is our premise that ethics represents a significant soft power force shaping the forefront of technology as sited above in the need for literacy for women and access to education for children. This example is a call to bridge the digital divide between rich and poor as noted in The Declaration of Principles adopted by the first UN-convened meeting of the World Summit on the Information Society (WSIS) in December 2003.

Dramatically in parallel is the verification regime developed under the Comprehensive Test Ban Treaty (CTBT) calling for an international monitoring system utilizing the finest technology known to man to ensure the safety of the planet. This is a technical and ethical challenge which must mobilize public opinion to ensure ratification. The United States is among the twelve remaining nations who have yet to sign the treaty and demonstrate integrity in the international community.

Rapidly evolving information technology inherits the values of modernization, which can result in a weakening of the frameworks of family, community, workplace, school and state. A positive aspect of diminishing the relevance of physical distance is that people who are geographically separate can now be part of global networks with access to many choices for positive expansion of freedom of action in involvement.

Influenced by the philosophy of Japanese educator Tsunesaburo Makiguchi and his American contemporary John Dewey, Dr. Ikeda reminds 
us that part of learning is sharing the life experience of peers while trying to grow as an individual oneself. The virtual environment can be speculative and detached from any quality inherent in effective learning and teaching. Computers and communications technology can never be a substitute for the actual human contact of dialog and face-to-face interaction of meetings and classroom instruction.

The challenge therefore is to cultivate ways of mentoring using information technology that embraces the lives and needs of the participants and their relative life condition. Creating an e-learning environment with effective curriculum tools that builds discipline necessary to apply those skills to the human condition is a major scientific and methodological challenge. This approach can be counterintuitive and should be one in which the learner is taught to know "the wound and shock of other's pain as our own" (John Dewey).

\section{DEFINING A GOOD LEARNING ENVIRONMENT}

One characteristic of good learning is a balance between critical and ethical education.

1. Critical: enhances the learner's critical thinking, enables the learning to think about his/her situation and face what is happening in the world. However, this can lead to discouragement, that is why some ethical guidelines are necessary.

2. Ethical: together with critical thinking and awareness, education needs to provide the learning with a sense of hope and courage, that there is something that can be done, based on the awareness one has gained.

In their dialogue in book form called "Choose Peace", Johan Galtung (the founder of modern peace studies) and Daisaku Ikeda (a renowned philosopher and Buddhist leader) agree that one needs a cool head and a warm heart in order to contribute to a better world. ${ }^{12}$

With only a cool head, the learner will not be able to have the inspiration necessary to contribute something new to society. With only a warm heart, the learner will try to find solutions without knowing what is really going on behind the scenes. Both are therefore needed, a cool head and a warm heart for critical ethical education. 


\section{WHAT MAKES A GOOD TEACHER?}

A good teacher or mentor cultivates rapport with the student building dialog that reinforces freedom in learning. Through discipline the student develops confidence in his or her grasp of methods and the relationship to technical thinking. In the e-learning environment this can be difficult since kinesthetic awareness is a component of learning integral to an engineer's working knowledge and grasp of dimension. Although one picture is worth a thousand words the appropriateness of knowledge based wisdom in education is always more effective when reinforced face-to-face through personal interaction with the teacher or mentor including the spatial component of guided discovery.

In building a mentoring model the internet makes it possible to communicate rapidly and in a group. Unfortunately it can also create myopic over engagement and egotism and an inability to think critically and creatively as an individual. The purpose of e-learning should not be to stimulate rote learning. For some students, the opportunity to work on their own time and according to their own hours of availability is very freeing with access to more than one instructor as a research guide and open hours of participation.

\section{THE INGREDIENTS IN LEARNING METHODS}

Evaluation of teaching methods cannot be isolated from the learning environment. Defining a context establishes parameters in which to include hands-on technical training and skill building with problem solving. We will site two examples, which illustrate a high degree of opportunity and success through e-learning. The first uses the internet as a conferencing tool and open forum for dialog and applied research. Founded by Dr. Olivier Urbain at Soka University in Japan this project is called the TAP network. Involvement includes continual online discourse, individual and collective applied projects, virtual art galleries and an online journal.

The TAP network is an ongoing conference of very active artists who participate in dialog sharing their passion and life work. The technical side of collaboration involves bulletin boards, and opportunities for posting papers to share ideas. (www.tapnet.info). The website is a free space and provides the opportunity to engage working concepts online which will contribute to the TAP community. Many wonderful and powerful projects have come from this innovative approach including art and spirituality and the refugee project (http://eartharc.com/invision/index.php?showforum=23) and(http://eartharc.com/invision/index.php?showforum=22). 
The second example of a successful case study is one in which Ebey was invited to participate as an online mentor to both a course about cinema and a course on the global environmental for an experimental class Dr. Urbain created for Soka University. In each case there were special projects by the students and lively, engaged online conferencing served to strengthen the work of the learners through dialog and formal electronic presentation. Course curriculum was outlined at the beginning followed by a highly participatory forum. The students diligently created websites, demonstrating prolific technical and artistic skill in their individual approaches to problem solving and fulfilling curriculum requirements. Collectively they responded to timely and relevant topics reflecting an interdisciplinary ability to cognitively organize responses to contemporary issues.

\section{CONCLUSION}

There are many factors to creating an effective e-learning environment that is academically rigorous both in the sciences and the arts. The challenge of responding to building human security through education is overwhelming and could potentially involve millions of people who otherwise would not have the opportunity to participate in the global community. To create a culture of peace educators must be critically aware and respond to the responsibility of engaged technical skills with wisdom and compassion and an eye to future generations.

\section{REFERENCES}

Bethel, Dayle (1994), Makiguchi, The Value Creator, Weatherhill, NY

Galtung, Johan and Ikeda, Daisaku, (1995) Choose Peace, Pluto Press, London

Ikeda, Daisaku, Soka Education, Middleway Press, Santa Monica, US

Daisaku Ikeda's 2004 Peace Proposal:

http://sgi.org/english/President/peaceproposal/peace2004.htm

TAP network http://tapnet.info 